\title{
The impact of endocrine disruptors on oocyte competence
}

\author{
P. Pocar ${ }^{1}$, T. A. L. Brevini ${ }^{2}$, B. Fischer ${ }^{1}$ and F. Gandolfi' ${ }^{2 *}$ \\ ${ }^{1}$ Department of Anatomy and Cell Biology, Martin Luther University, Halle (Saale) Germany; and \\ ${ }^{2}$ Department of Anatomy of Domestic Animals, University of Milan, 20133 Milan, Italy
}

To date, approximately 60 chemicals have been identified as endocrine disruptors: exogenous agents that interfere with various aspects of natural hormone physiology. The potential reproductive and health hazards of these environmental chemicals have recently generated concern among the scientific community, policy makers and general public. The present review presents and discusses the available evidence that environmental chemicals are causing ovarian toxicity in various species, with particular attention to farm animals. The impact of chronic exposure to endocrine disruptors via food and drinking water cannot be neglected when studying fertility problems in these species. This review focuses attention on the superfamily of organochlorine chemicals, persistent organic pollutants (POPs), because of their persistence in the environment, ability to concentrate up the food chain, continued detection in environmental matrices and ability to be stored in the adipose tissue of animals and humans. Published data clearly indicate that POPs disrupt mammalian oocyte maturation and follicle physiology in every species studied so far, including farm animals. However, as most of the data available still derive from experiments performed on laboratory species or in vitro models, great care should be taken when extrapolations to other species or environmental situations are attempted.

Recently, there has been concern among the scientific community, policy makers and general public regarding the potential reproductive and health hazards of a range of environmental chemicals known as 'endocrine disruptors'. An endocrine disruptor is defined as an exogenous agent that interferes with the synthesis, secretion, transport, metabolism, binding, action or elimination of natural blood-borne hormones in the body that are responsible for homeostasis, reproduction and developmental processes (Kavlock and Ankley, 1996). Like hormones, small amounts of these chemicals (parts per trillion) are believed to affect the endocrine system of animals and humans.

Three main types of endocrine-disrupting mechanism have been identified:

- Mimics imitate naturally produced hormones such as oestrogen and testosterone. These chemicals can initiate chemical reactions in the body in the same way as naturally produced hormones.

- Hormone blockers 'lock up' a hormone receptor, preventing naturally produced hormones from entering the cell and performing their function.

- Triggers act through hormone-like pathways but initiate abnormal reactions in the cell that would not normally be produced by a hormone. The best-known triggers

*Correspondence

Email: fulvio.gandolfi@unimi.it are dioxin and dioxin-like chemicals. Dioxin acts through a hormone-like process to initiate entirely new responses.

To date, approximately 60 chemicals have been identified as endocrine disruptors. Chemicals with hormonal activity fall into three broad classes: (1) synthetic chemicals used in industry, agriculture and consumer products; (2) synthetic chemicals used as pharmaceutical drugs; and (3) natural chemicals found in human and animal food (phytoestrogens). Examples of these substances are provided (Box 1). About half of these compounds are chlorinated, including dioxins (PCDDs), polychlorinated biphenyls (PCBs) and organochlorine pesticides such as DDT, methoxychlor, dieldrin and hexachlorcyclohexane $(\mathrm{HCH})$. Exposure to endocrine disruptors can occur in a variety of ways; humans and animals can be exposed involuntarily to endocrine disruptors as a result of drinking contaminated water, breathing contaminated air, ingesting food or coming into contact with contaminated soil.

Although endocrine disruptors have adverse effects on different hormone-dependent functions, for example, immune and thyroid dysfunction (Smialowicz et al., 1989; Vos and van Loveren, 1995), studies have focused mainly on development and reproduction. The interference by endocrine disruptors of normal development of male and female reproductive organs as well as with reproductive functions in adulthood 
Box 1. Synthetic compounds known as or suspected to be endocrine disruptors

Herbicides and fungicides

- Dichlorophenoxyacetic acid (2,4-D)

- Trichlorophenoxyacetic acid (2,4,5-T)

- Alachlor

- Amitrole

- Atrazine

- Metribuzin

- Nitrofen

- Trifluralin

- Benomyl

- Mancozeb

- Zineb

- Metriam complex

- Maneb

- Ziram

- Tributyltin

- Hexachlorobenzene

Insecticides

- Benzenehexachlorcyclohexane (B-HCH)

- Methoxychlor

- Toxaphene

- DDT and metabolites (DDE)

- Carbaryl

- Endosulfan

- Mirex

- Transnonachlor

- Chlordane

Nematocides

- Aldicarb

Industrial chemicals

- Dioxins

- Polychlorinated biphenyls (PCBs)

- Polybrominate biphenyls (PBBs), pentachlorophenol (PCP)
- Oxychlordane

- Dicofol

- Heptachlor and heptachlor epoxide

- Dieldrin

- Parathion

- Methomyl

- Lindane $(\mathrm{Y}-\mathrm{HCH})$

- Synthetic pyrethroids

- Chlordecone (kepone)

- 1,2-Dibromo-3-chloropropane (DBCP)

- Penta- to nonyl phenols

- Phthalates

- Styrenes has been well documented, in both wildlife and experimental animals (for reviews, see Colborn et al., 1993 and Toppari et al., 1996). In females, published data indicate that exposure to chemicals may cause alterations in reproductive behaviour and contribute to sub-fecundity, infertility, pregnancy loss, growth retardation, intrauterine fetal demise, birth defects and ovarian failure (for reviews, see Sharara et al., 1998 and Bhatt, 2000).

In adult females, the reproductive cycle is a complex process characterized by the distinct phases of gametogenesis and embryogenesis. Each of these phases is under the control of steroid hormones (Knobil and Neill, 1988) and is therefore a potential target for endocrine disruptors. It has been demonstrated that increased concentrations of xenoestrogens may affect ovarian function through the disruption of feedback mechanisms in the hypothalamus-pituitary-gonadal axis (Crisp et al., 1998). Moreover, the ovarian follicle has also been shown to be a direct target for xenoestrogens (Davis et al., 1994; Hoyer, 1999; Wojtowicz et al., 1999). Collectively, these studies show that endocrine disruptors can influence follicular growth and, through these effects, may also affect the oocyte, as has been shown in in vitro studies (Hafne et al., 2000).

\section{Environmental chemicals affect ovarian function in different ways}

Female reproductive function can be compromised by exposure to toxic chemicals (Mattison, 1985) at a variety of sites, including the hypothalamus, pituitary gland, ovary and reproductive tract (Mattison, 1980; Thomas, 1993). Disruption of any of these sites can ultimately manifest as a disruption of ovarian function, resulting in infertility.

The ovary performs two important roles, delivery of the female gametes (oocytes) and production of ovarian hormones, for example oestrogen, progesterone and inhibin (Richards, 1980; Hirshfield, 1991). How reproductive toxicants can affect ovarian function is generally not well understood but the effects can be due to one of several possible mechanisms. Sites of action include the hypothalamus-hypophyseal system, resulting in disruption of the normal pattern of gonadotrophin secretion, and the ovary, resulting in direct destruction of the oocyte (ovotoxicity).

Oocyte destruction can result from a toxic chemical directly impairing oocyte viability. However, as oocytes at all stages of development are surrounded by follicular cells, these mechanisms might also be 
indirect, involving alterations within the follicular wall, which compromise its ability to maintain oocyte viability (Buccione et al., 1990). Extensive oocyte destruction damages ovarian follicles and, in turn, destroys steroid hormone production, which can result in ovarian failure. Therefore, oocyte destruction, ultimately, can disrupt the endocrine balance, causing a reduction in oestrogen and progesterone and an increase in FSH and LH. Finally, endocrine disruptors can affect other organs, leading indirectly to altered ovarian function, for example, through metabolic alterations that change the balance of feedback control of the hypothalamus-pituitary-ovarian system.

Susceptibility of the ovaries to the different classes of agent depends on the stage of development at which exposure occurs. For chemicals that destroy the oocytes, the stage of development at which the follicle is destroyed determines the impact that the exposure to the chemical will have on reproduction. Compounds that extensively destroy oocytes contained in primordial and primary follicles may have a delayed effect on reproduction until recruitment of growing and antral follicles can no longer be supported (Generoso et al., 1971; Hooser et al., 1994). Conversely, chemicals that selectively damage large growing or antral follicles generally interrupt reproductive function only temporarily because these follicles can be replaced by recruitment from the greater pool of primordial follicles. Thus, these chemicals produce a readily reversible infertility that is manifest relatively soon after exposure (Jarrell et al., 1991; Davis et al., 1994).

The concentration of endocrine disruptor required to produce ovarian damage is another factor that determines the final effect of the exposure to a reproductive toxicant. It is only under rare circumstances that individuals are exposed acutely to toxic concentrations of ovotoxic chemicals, and the effects can usually be detected and evaluated. However, the effects of chronic exposure to toxicants are more difficult to determine. Because of the insidious nature of toxicants, this type of exposure can cause 'silent' damage and is of the greatest concern.

Environmental chemicals can alter ovarian function acting both upstream and downstream from the ovary itself. Moreover, when the ovary is the target, consequences depend on the stage of follicular development, and the dose and duration of exposure.

\section{The organochlorine chemicals superfamily}

The present review discusses the evidence that environmental chemicals are causing ovarian toxicity in various species, with particular attention to farm animals. To date, the physiological consequences of the ingestion of endocrine disruptors by farm animals are largely unknown. However, the extent of exposure of domestic ruminants to these chemicals is such that the impact of exposure to endocrine disruptors via food and drinking water cannot be neglected when studying fertility problems in these species. Indirect evidence of adverse effects is provided by a study that demonstrates an association between exposure to drinking water contaminated with sewage overflows and reduced reproductive performance of dairy cattle (Meijer et al., 1997). Monitoring the adverse effect of endocrine disruptors on reproduction is important for the animal production industry, which is vulnerable to the inadvertent disposal of potentially dangerous chemicals. In particular, it is important to study the effect of endocrine disruptors on female reproductive physiology, as farm animal reproduction is based on the intensive use of a limited number of males, usually under strict management, and on the extensive use of a large number of females exposed to a wide range of different environmental conditions.

This review focuses attention on the superfamily of organochlorine chemicals (persistent organic pollutants, POPs) because of their persistence in the environment, ability to concentrate up the food chain, continued detection in environmental matrices and ability to be stored in the adipose tissue of animals and humans.

POPs comprise a superfamily of chemicals persistent in the environment and with adverse effects on health and environment. Members of this superfamily include polychlorinated dibenzo- $p$-dioxins (PCDDs), polychlorinated dibenzo furans (PCDFs), polychlorinated biphenyls (PCBs), polychlorinated diphenyl ethers (PCDEs) and polychlorinated naphthalenes (PCNs), as well as the polybrominated biphenyls (PBBs) and polybrominated diphenyl ethers (PBDEs). Each subfamily consists of many congeners that share the chemical backbone of the subfamily but have different numbers and positions of halogen substituents. The molecular structure of some of the most common POPs is shown (Fig. 1). Many of these compounds have four characteristics that make them intrinsically hazardous:

- Long environmental half-lifes (persistent), resulting in a continued increase of the global inventory in the environment.

- Can be found at great distances from where they are used or released (Fig. 2).

- Characterized by low water solubility and high lipid solubility, leading to their bioaccumulation in fat tissues.

- Many of these compounds possess sex steroid activities, thereby causing endocrine disruption and a number of associated effects such as reproductive system dysfunction.

The stability and lipophilicity of POPs has led to increased concerns regarding the toxic effects that they can exert on a range of biota even at extremely low concentrations, in particular on species at the top of the food chain. Moreover, high concentrations of 


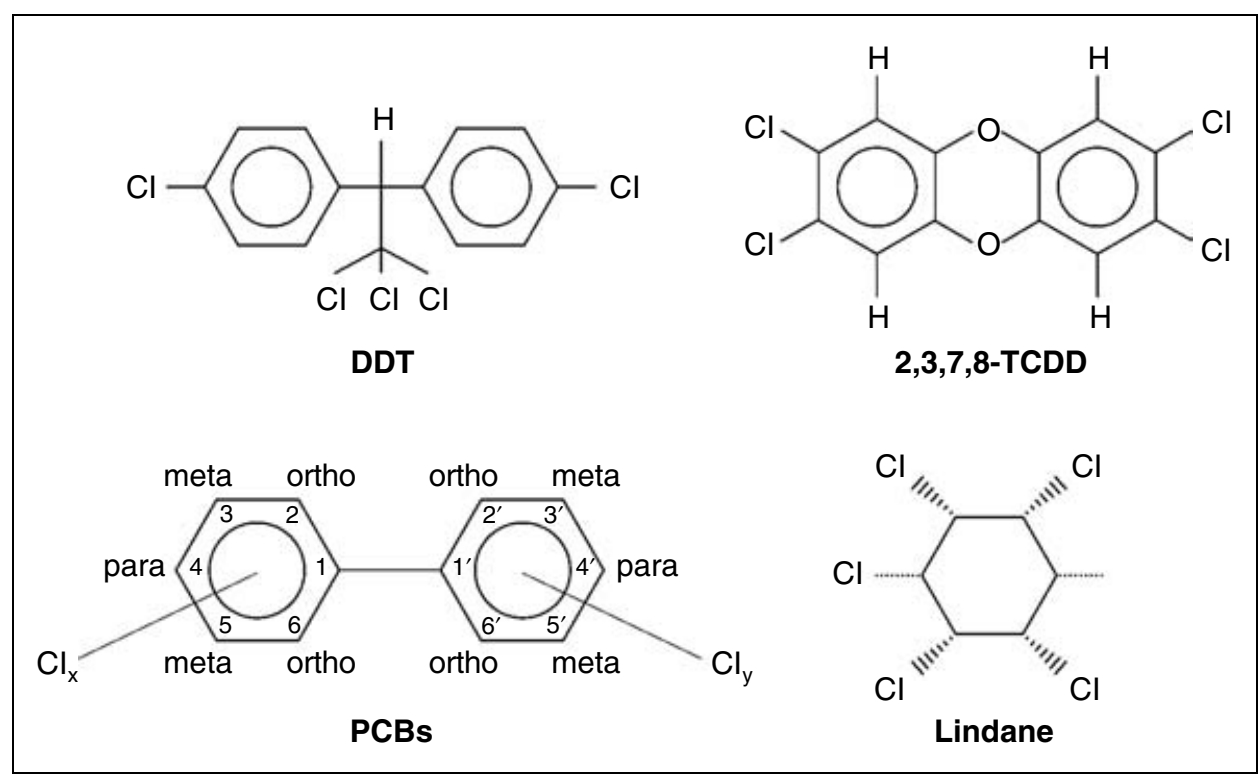

Fig. 1. Molecular structure of some of the most common persistent organic pollutants. DDT: dichlorodiphenyltrichloroethane; PCBs: polychlorinated biphenyls; TCDD: tetrachlorodibenzo- $p$ dioxin.

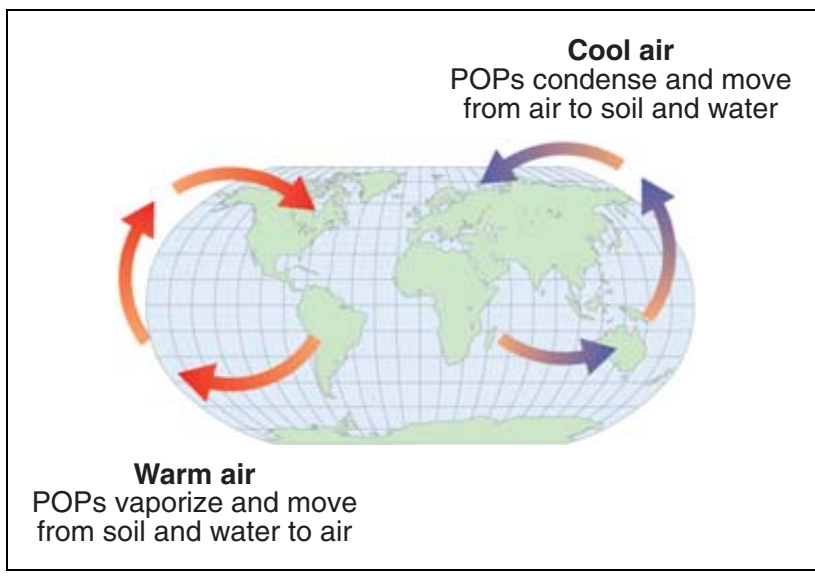

Fig. 2. Schematic representation of the current theory on the global transport of persistent organic pollutants (POPs). Organochlorines tend to vaporize from soil and water in the mid-latitudes, travel about the earth and condense when they encounter colder air, returning to earth and working their way through food webs.

POPs are known to be present in sewage sludge from industrial, agricultural and domestic sources, which is spread on arable land and pasture as fertilizer (Wild and Jones, 1992), and are found in water (Fingler et al., 1992; Abbassy et al., 1999). Farm animals ingest these substances with food and drinking water and it is likely that the rate of ingestion will increase in the future as increased amounts of sewage sludge are recycled onto agricultural land (Wild and Jones, 1992). Rhind et al. (2002) investigated the accumulation of endocrine disruptors other than POPs (for example, phthalates and alkylphenols) on agricultural land after sewage sludge treatment. Although the authors concluded that there is no significant long-term accumulation of the investigated endocrine disruptors in pastures after repeated sludge application, they also observed a relatively high concentration of endocrine disruptors in control areas. Therefore, the potential remains for the ingestion of endocrine disruptors by grazing animals to be biologically relevant, and a better understanding of the potential risk of sludge contamination on agricultural land will require the assessment of pasture accumulation rate for a broader range of chemicals, including POPs.

The present review covers the adverse effects on oocyte competence of only three POP subfamilies, that is PCDDs, PCBs and organochlorine pesticides. Although there may be concern about the reproductive toxicity of other classes of compound (for example, PBDEs) this study focuses attention on chemicals that have been quantified in reproductive tissues and in ovarian follicular fluid (Trapp et al., 1984).

\section{Polychlorinated dibenzo-p-dioxins}

PCDDs are environmental contaminants, historically derived from industrial processes such as herbicide production, chlorination and combustion. PCDDs consist of up to 75 congeners (Safe, 1986) and can induce a diverse spectrum of biochemical and toxic responses in laboratory animals and mammalian cells in culture (Poland and Knutson, 1982). Among PCDDs, 2,3,7,8tetrachlorodibenzo- $p$-dioxin (TCDD) is considered the most toxic and one of the most potent environmental toxicants (DeVito and Birnbaum, 1995). The bestcharacterized mechanism for the action of TCDD is the 
arylhydrocarbon receptor (AhR, Fig. 3; Burbach et al., 1992), which is present in the cytoplasm bound with at least three additional proteins (Hankinson, 1995). These proteins are thought to keep the AhR in a state responsive to ligand binding. Regulatory proteins are displaced when ligand binding occurs, and the AhR enters the nucleus where it complexes with its nuclear partner AhR nuclear translocator (Arnt; Hoffman et al., 1991). The newly formed heterodimer acquires the ability to bind specific DNA enhancer sequences known as xenobiotic responsive element (XRE; Denison and Wilkinson, 1985), acting as a transactivator of gene expression in a wide variety of species and tissues (Denison and Wilkinson, 1985; Dolwick et al., 1993). Generally, products of these genes are of one or two broad categories: drug-metabolizing enzymes and growth-regulatory proteins. The most extensively studied AhR-target gene is cytochrome P450 1A1 (CYP 1A1), a protein involved in the metabolism of a large number of xenobiotics (Delescluse et al., 2000), and which also plays an important role in oestrogen metabolism (Zhu and Conney, 1998). Changes in these metabolic enzymes do not appear to mediate directly the effects of the ligand. However, they play an important role, transforming 'pretoxicants' into their ultimate cytotoxic form or detoxifying potentially dangerous xenobiotics. Several genes that encode growth-regulatory proteins also appear to be responsive to AhR agonists. This group includes the epidermal growth factor receptor, the oestrogen receptor, interleukin $1 \beta$ and transforming growth factors $\alpha$ and $\beta$. There has been no direct demonstration that changes in expression of any of these genes are responsible for the toxic effects of TCDD-like compounds, but recent work indicates that some of the oestrogen-related genes and growth factors can play a critical role in the toxic action of TCDD (Yang et al., 1999).

The effects of TCDD on sexual development and fertility have been extensively documented (Peterson et al., 1993) and recent investigations have reported that TCDD can also compromise ovarian function. Human follicular fluid contains TCDD (Tsutsumi et al., 1998) and the presence of a functional AhR has been shown in the ovarian tissues of several species, including rats (Son et al., 1999), primates (Chaffin et al., 1999), mice (Robles et al., 2000) and cows (Fischer et al., 2001). Exposure to TCDD is associated with significantly lower ovarian masses compared with controls in rats (Gao et al., 1999; Son et al., 1999), irregular oestrous cycle among rhesus monkeys (Allen et al., 1977; Barsotti et al., 1979) and loss of ovarian cyclicity in adult rats ( $\mathrm{Li}$ et al., 1995; Cummings et al., 1996). Further investigations have shown that TCDD administration to rats before mating interrupts fertility via effects on ovulation (Giavini et al., 1983; Chaffin et al., 1996). Similar effects have been observed in hypophysectomized animals (Gao et al., 1999) and after direct application of TCDD to the

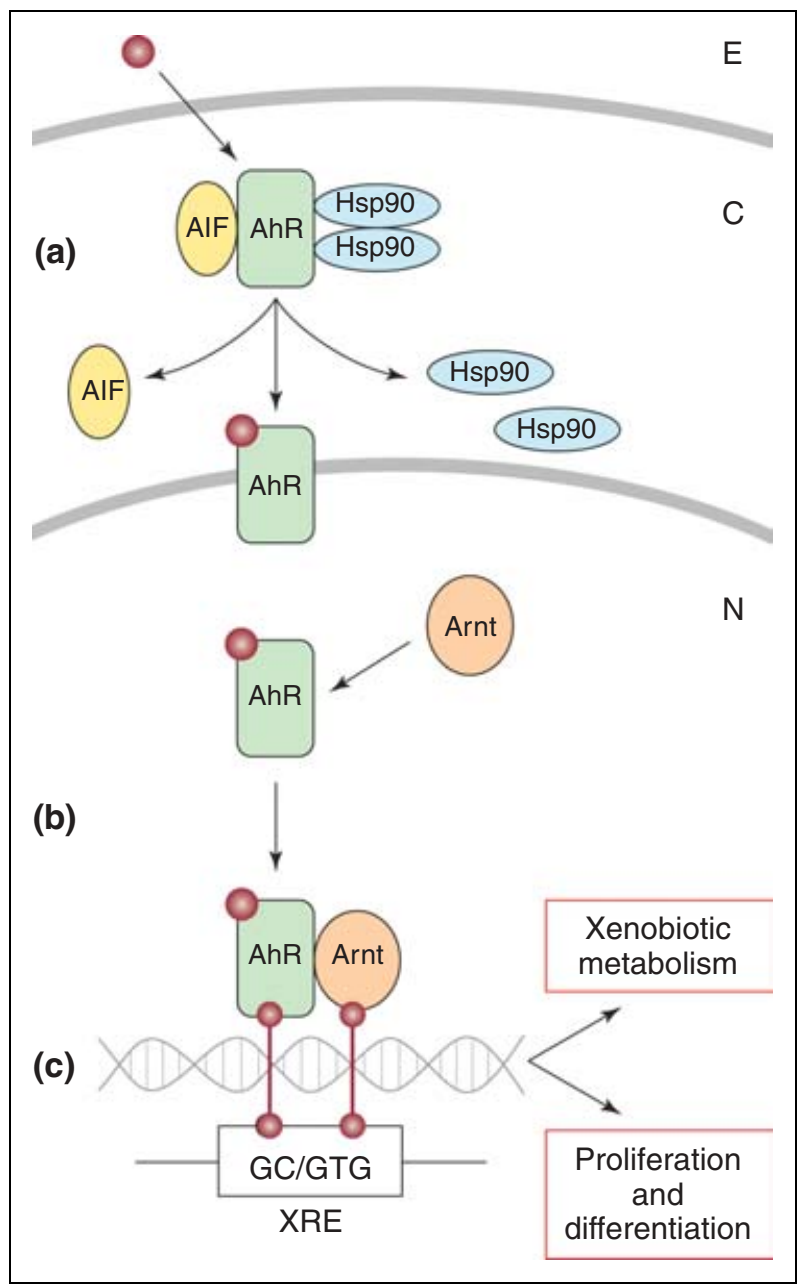

Fig. 3. Outline of the arylhydrocarbon receptor (AhR) function as a ligand-activated transcription factor. (a) AhR resides in the cytoplasm (C) complexed with the AhR interaction factor (AIF) and two molecules of heat shock protein 90 (Hsp90). The ligand diffuses through the membrane from the extracellular side $(E)$ and binds the AhR. (b) Ligand-bound AhR enters the nucleus (N) and dimerizes with the Ah receptor nuclear translocator (Arnt). (c) The AhR-Arnt complex binds the sequence GC/GTG specific for xeniobiotic responsive element (XRE) and activates target gene transcription. Genes that are under control of the AhR belong to two major functional groups: (1) Genes coding for drug-metabolizing enzymes, the induction of which can alter the biotransformation activity for endogenous and exogenous substances, potentially leading to both beneficial and detrimental effects. (2) Aberrant regulation of genes that regulate cell proliferation and differentiation may underlie the toxic manifestations of many aromatic hydrocarbons.

ovary (Petroff et al., 2000), indicating that the ovary can be a target organ for TCDD toxicity.

\section{Polychlorinated biphenyls}

PCBs are a group of halogenated aromatic hydrocarbons that consist of 209 isomers and congeners with 
different numbers and positions of chlorine atoms substituted on the biphenyl moiety. PCBs were synthesized for approximately 60 years from the early 1920s until they were banned in many countries during the late 1970s. Uses of PCBs varied from closed-system applications in capacitors and transformers to open-system applications in the manufacture of adhesives, textiles and printing. Such a plethora of uses has facilitated the ubiquity of PCBs in the environment. It is estimated that $10^{8} \mathrm{~kg}$ of PCBs still reside in the biosphere (Boyle et al., 1992).

PCBs are small molecules (molecular weight 188498) with a low solubility in water but high solubility in organic solvents, oils and fat (Ballschmiter et al., 1989). As a result of this lipophilic nature, stability and resistance to degradation, PCB congeners can be found at all levels of the food chain and can accumulate in the animal and human body (Jones, 1988; McFarland and Clarke, 1989). Measurable concentrations of these compounds are found not only in the adipose tissue, but also in fluids of the female genital tract (Lindenau et al., 1994). Trapp et al. (1984) demonstrated measurable concentrations of these chlorinated hydrocarbons in the follicular fluid of women and highlighted the potential threat to reproductive health posed by these contaminants. Measurable concentrations have been detected in human ovarian tissue (Mes et al., 1990), embryos and fetuses (Nishimura et al., 1977). It appears that PCBs have a systemic effect on reproduction with multiple targets, but the affected biological functions have not yet been identified precisely. Rodents exposed to PCBs experience a reduction in the number of germ cells, a decrease in weight of the reproductive organs, a reduced number of implantation sites, embryo toxicity and reduced litter size (d'Argy et al., 1987; Linzey, 1988; Ronnback and de Rooij, 1994). Furthermore, a perturbing effect on the hypothalamic enzyme aromatase, involved in the control of sexual differentiation of the developing brain, has been found after prenatal exposure of rats to PCBs (Brevini-Gandolfi et al., 1999a). Reproductive disorders have also been observed in nonhuman primates. Alterations of the menstrual cycle and increased incidence of abortions and embryo resorption are observed in monkeys exposed to Aroclor 1248 (Barsotti et al., 1976). Some of these studies indicate direct and indirect effects of PCBs on ovarian function. For example, in rats exposed to the commercial mixture A-1242, a reduction in the number of follicles is observed (Jonsson et al., 1975). In rhesus monkeys, administration of PCBs alters the menstrual cycle, induces amenorrhoea (Barsotti et al., 1976) and inhibits ovulation in 50\% of treated animals (Muller et al., 1978).

\section{Organochlorine pesticides}

Organochlorine chemicals that have been identified as possible or definite endocrine disruptors are pesti- cides such as DDT, lindane and methoxychlor (MXC). Generally, the chemical structure of organochlorine pesticides is based on a benzene ring with one or more chloride atoms attached. Like the other POPs described, the organochlorine pesticides are harmful to all living systems, due to their high affinity for fat tissue, and to their persistence in the environment. Their half-life is at least 20 years in both soil and water, and some soils retain up to $38 \%$ of the amount originally applied (Martijn et al., 1993). This group of pesticides can bioaccumulate in the food chain due to their fat solubility (Clarkson, 1995). In the 1970s most industrialized countries banned compounds like DDT because of their ability to accumulate. However, in developing countries some of these pesticides are still in use, particularly for mosquito control, but also in general agriculture, due to high efficiency and relatively low cost. Environmental concentrations of residues were reduced after organochlorine pesticides were banned in industrialized countries, until an equilibrium was reached in the 1980s. These compounds are still present in the environment due to their resistance to biodegradation: the half-life of DTT and some of its metabolites can be more than 50 years. Body fat concentrations recorded in humans are still fairly high, particularly in developing countries (up to approximately $60 \mathrm{mg} \mathrm{g}^{-1}$; Rivero-Rodriguez et al., 1997).

The adverse effects on reproduction of organochlorine pesticides are well documented. The effects of DTT in experimental animals include decreased fertility, abortion and stillbirths. Multigenerational studies in rodents show that DDT decreases general fertility and gonadal mass, increases the duration of the oestrous cycle, decreases the number of implantations, increases the rate of embryo mortality, decreases litter size and increases the duration of gestation (Coulston, 1985). MXC was developed to replace DDT and it is considered to be less toxic. However, reports demonstrate that it can influence the function of the reproductive system (Bal, 1984). For example, reduced litter size and increased rate of abortion is observed in rabbits and rats orally exposed to MXC (Khera et al., 1978). Furthermore, longterm oral exposure of rats to MXC reduces maternal fertility and increases fetotoxicity, as well as reducing fertility in offspring (Cummings and Gray, 1987). Finally, female rabbits treated with lindane show a significantly reduced ovulation rate (Lindenau et al., 1994). Observations indicate that these three toxicants are interfering mainly with oestrogen-mediated activities and recent studies indicate a direct effect on the ovary and oocyte.

On the basis of the studies described above, it is clear that POPs present a real danger and have a welldemonstrated negative effect on female reproductive efficiency. The specific effects that these chemicals exert on the oocyte will now be discussed. 


\section{Sites of ovotoxicity}

\section{Ovarian development}

An important factor related to the effect of exposure to a reproductive toxicant is the developmental stages in the reproductive lifespan at the time of exposure. Temporary infertility may be manifest in adult cyclic females, but sterility might be produced by a chemical-induced destruction of germ cells during fetal development. The developing embryo and fetus, in fact, appear to be more sensitive than adults to endocrine disruption, and alterations in reproductive development are normally observed at a concentration much lower than that able to induce toxicity in adult animals. Rapidly dividing primordial germ cells and oogonia present during fetal development in all species are highly sensitive to destruction by a variety of environmental chemicals (Hoyer and Sipes, 1996). Ironically, it is the fetus that receives significant exposure or the greatest body burden of environmental POPs. As evidence of fetal exposure, offspring at birth have concentrations of TCDD that are up to $25 \%$ of maternal concentrations (Masuda et al., 1978; Jacobson et al., 1984; Koppe et al., 1992). This uptake of polyhalogenated POPs by the fetus raises concerns about the potential for adverse health outcomes. To date, few studies have investigated the effects of prenatal exposure to persistent organic pollutants on ovarian development. In utero exposure to TCDD adversely affects reproductive function and anatomy in female rodent offspring, resulting in permanently reduced ovarian mass, decrease in the number of corpora lutea, premature ovarian senescence and early decline in fertility and fecundity (Silbergeld and Mattison, 1987; Gray et al., 1997; Wolf et al., 1999). Prenatal exposure to dioxin-like PCBs has been shown to reduce the number of germ cells in the ovaries by $40-50 \%$. This decrease appears in all stages of oocytes and follicles and leads to premature reproductive ageing (Ronnbck, 1991). The similarity between the effects noted after exposure to dioxin-like PCB congeners or TCDD (Smitsvan Prooije et al., 1992; Gray and Kelce, 1996) indicates that the arylhydrocarbon receptor might be involved in the reproductive effects observed. Matikainen et al. (2002) hypothesized that AhR has a prominent role in regulating apoptosis during female gametogenesis and is a possible mediator of fetal ovarian germ loss.

\section{Oocyte maturation}

Oocyte maturation is a critical prerequisite for subsequent fertilization and development. Thus, disruption of this process has considerable potential to impair female reproduction. Oocyte destruction by environmental chemicals requires that these compounds reach the ovary. After Trapp et al. (1984) reported that various organochlorine persistent chemicals such as PCBs, PCDDs and DDT are present in the follicular fluid, the presence of $\mathrm{PCBs}$ was confirmed at a concentration ranging from 4.7 to $27 \mathrm{ng} \mathrm{ml}^{-1}$ (Kholkute et al., 1994) and similar concentrations have been found in human plasma (Swain, 1991; Ayotte et al., 1997). Therefore, ovaries and follicles are exposed to environmental organochlorines as are most other organs in the body.

The ovotoxic potential of PCBs has been studied in different species using in vivo and in vitro models. However, very few studies have been conducted on the possible toxic effects of PCBs on mammalian oocytes. Preliminary observations indicate that human embryos derived from oocytes contained in follicles with increased pollutant concentrations have low cleavage rates after IVF (Trapp et al., 1984).

Kholkute et al. (1994, 1997) tested the effects of PCB mixtures, such as A-1254 and 1268, on the in vitro maturation and fertilization of mouse oocytes. The results indicate that the addition of PCB mixtures to the maturation medium, at concentrations ranging from 0.01 to $10 \mu \mathrm{g} \mathrm{ml}^{-1}$, affect the fertilizing capability of the oocytes. Exposure to A-1254 at a concentration of $10 \mu \mathrm{g} \mathrm{ml}^{-1}$ failed to reveal any significant effect on the viability of the oocytes, although morphology and structural changes were not evaluated (Kholkute et al., 1994). Furthermore, Greenfeld et al. (1998) observed that A-1254 at the same concentrations did not affect the fertilization competence of exposed cumulus-free mouse oocytes, indicating a possible role of cumulus cells in PCB-induced toxicity.

At present, only two main studies have been conducted to evaluate the effects of PCBs on bovine oocytes. Krogenaes et al. (1998) demonstrated that the addition of PCBs 153 (non-coplanar) or 126 (coplanar) to the maturation medium has adverse effects on bovine oocytes. In particular, PCB 153 has no effect on maturation but reduces the percentage of oocytes able to complete the first mitosis after fertilization, whereas PCB 126 shows adverse effects on maturation only at the highest concentrations, but affects the subsequent embryo development also at lower levels of exposure. Pocar et al. (2001a) investigated the adverse effects of exposure of bovine oocytes during the maturation process to A-1254. This is a technical mixture of PCBs, the composition of which is considered to be environmentally relevant. A-1254 significantly decreases the percentage of oocytes that can reach metaphase II at concentrations as low as $0.01 \mu \mathrm{g} \mathrm{ml}^{-1}$. This effect is probably caused by a block or a delay of the maturation process, as a significant percentage of the exposed oocytes is arrested at metaphase I. Furthermore, exposure to PCBs during maturation significantly decreases the fertilization ability of oocytes while increasing polyspermy. The negative effect of the addition of A-1254 to the maturation medium appears 
not to be limited to maturation and fertilization, but includes embryonic development, as there is a significant decrease in the proportion of cleaved embryos reaching the blastocyst stage. Consistent with the results of Krogenaes et al. (1998), fertilization and embryonic development are affected by a PCB concentration $\left(0.001 \mu \mathrm{g} \mathrm{ml}^{-1}\right)$ lower than that required for inducing the reduction of maturation rate. It is important to note that the concentration range used in these studies is comparable to that observed in the serum of nonexposed women $\left(0.001\right.$ and $0.4 \mathrm{ngg}^{-1}$ for PCBs 126 and 153, respectively; Johansen et al., 1994), which, in turn, is similar to the concentrations of persistent organic pollutants in follicular fluid (Kimbrough, 1995). Moreover, PCB 153, as a major and very stable PCB congener, has been shown to correlate directly with the total amounts of PCBs (Pauwels et al., 1999). However, at present, no data are available on the PCB concentrations present either in cattle serum or follicular fluid. Such concentrations, in fact, could be significantly different from those recorded in humans as a result of the difference of diet and digestive physiology between the two species. However, PCBs are not the only organochlorine compounds that induce oocyte toxicity in farm animals. Alm et al. (1998) studied the effects of in vitro exposure of bovine oocytes to DDT, lindane (hexachlorocyclohexane or gamma $\mathrm{HCH}$ ) and MXC. All of these pesticides affect maturation rate in a dose-dependent manner, but to different extents. The higher concentrations of pesticides are associated with higher rates of chromatin degeneration, up to $50 \%$. Furthermore, DDT and gamma $\mathrm{HCH}$ concentrations that do not decrease fertilization rates induce a significant reduction of embryos developed to the morula and blastocyst stage by days 7 and 8 after IVF, the commonly used parameter for normal development in vitro. This result is similar to that observed in the experiments with PCBs but did not occur with MXC.

The observation that for PCBs, DDT and gamma $\mathrm{HCH}$, a low-dose effect on oocyte developmental competence is delayed and visible only at the later stages of embryo preimplantation development is of particular significance because it indicates that the analysis of all phases of development is necessary for the full assessment of the risk posed by these compounds.

All of the studies described evaluated the toxic effects of only one class of POPs at a time, an experimental approach essential for understanding the mechanism of action of each POP. However, Campagna et al. (2001) used an environmentally relevant mixture of more than 15 organochlorines (including PCBs, DDT, its metabolite DDE, and lindane) to investigate the effect of these chemicals on in vitro maturation of pig oocytes. This study has a particular ecological significance as mixtures, not individual compounds, have been used industrially and have accumulated in the environment. An environmentally relevant mixture provides a better representation of conditions because it contains components that can interact with each other in an additive or non-additive fashion (synergistic or antagonistic), and can interact with different receptors and molecular pathways. Campagna et al. (2001) demonstrated that exposing pig oocytes to an organochlorine mixture during in vitro maturation negatively affects the maturation rate, without increasing degeneration rate. Developmental competence of the exposed oocytes is also affected, reducing blastocyst rate and quality in a dose-dependent manner. Furthermore, there is a decrease in the quality and viability of cumulus cells, which may account for reduced maturation and developmental competence.

\section{Mechanisms of ovotoxicity}

The intracellular mechanisms involved in organochlorine ovotoxicity are only beginning to be understood. In the studies described, maturation stages were determined by the evaluation of nuclear morphology. However, this evaluation did not allow for assessment of cytoplasmic maturation, a process through which immature oocytes acquire the competence to be fertilized and to sustain embryo development. Cytoplasmic maturation is characterized by ultrastructural and spatial rearrangements of the ooplasm as well as by chemical changes of the molecules stored therein (Hyttel et al., 1997; BreviniGandolfi and Gandolfi, 2001). For this reason, a set of experiments was designed to examine the effects of the exposure of bovine oocytes to a dose of A1254 known to be detrimental to nuclear maturation and embryo development, on two important aspects of cytoplasmic maturation: modulation of maternal mRNA polyadenylation (Brevini-Gandolfi et al., 1999b) and migration and exocytosis of cortical granules (Damiani et al., 1996).

\section{Alteration of mRNA stored in the ooplasm}

It is generally accepted that mRNA and protein molecules synthesized during oocyte growth and maturation contribute to early development before embryonic genome activation (Telford et al., 1990). The storage of mRNA takes place during oocyte growth and the extent of $\operatorname{poly}(\mathrm{A})$ tail at the $3^{\prime}$ end of the transcripts (Fig. 4) has emerged as an important regulatory element for determining stability (Richter, 1996) and represents a key regulatory step for early embryonic development (Vassalli and Stutz, 1995; Brevini-Gandolfi et al., 1999b). Results show that A-1254 induces changes to the polyadenylation pattern of five out of ten genes examined, indicating a perturbing effect exerted by this contaminant on the translational regulation of these transcripts. However, PCB action on polyadenylation seems to be different from that of other factors affecting oocyte competence. For instance, when reduction of developmental competence is induced by removing gonadotrophins 


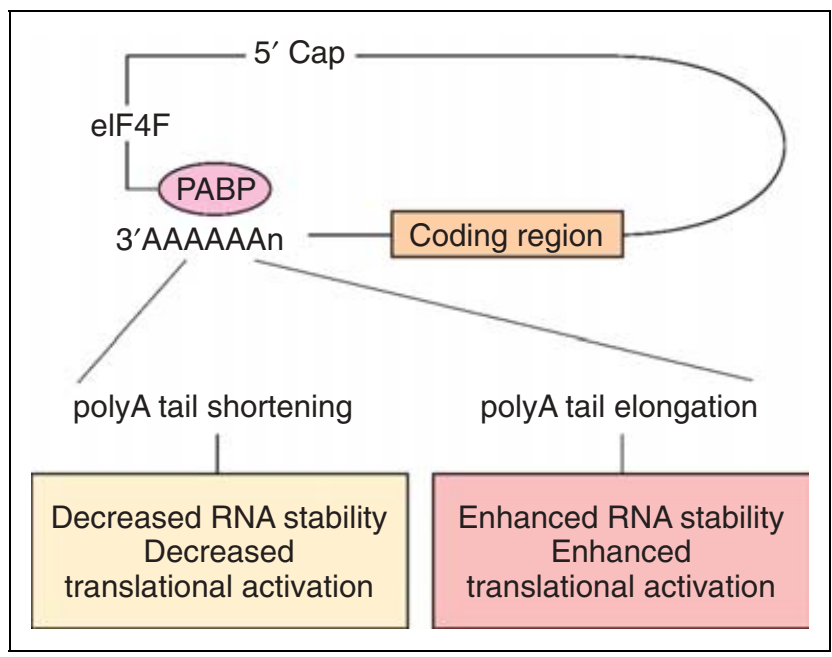

Fig. 4. Post-transcriptional regulation of gene expression relies on two main modulatory systems: targeted degradation of mRNA and control of translation initiation and activity. The half-life of individual mRNAs may vary from a few minutes to many days and depends on degradation by specific exonucleases. RNA molecules are protected from the attack of these enzymes by a $5^{\prime}$ methylguanosine cap structure ( $5^{\prime}$ Cap) and a 3'polyA tail of adenosine residues ( $3^{\prime} \mathrm{AAAAAn}$ ), which together interact in controlling mRNA stability and decay. Shortening of the polyA tail and $5^{\prime}$ decapping allows exonucleolytic degradation of the mRNA and is followed by rapid decay of RNA molecules. PolyA tail elongation, by contrast, prevents enzymatic degradation and increases mRNA stability. $5^{\prime}$ and $3^{\prime}$ ends are also involved in the regulation of translation: mRNAs with high base homology at the two ends form stable secondary structures that prevent access to the translation start site, causing very inefficient translation. Translational activity is conversely enhanced by polyA tail elongation that causes binding of a polyadenylation binding protein PABP to a specific translation factor elF4F.

from the maturation medium, only those transcripts that would normally undergo deadenylation during the maturation process display an alteration of the poly $(\mathrm{A})$ tail. Transcripts that either become adenylated or do not change during maturation are not affected by the absence of gonadotrophins (Brevini-Gandolfi et al., 1999c). On the contrary, exposure of oocytes to A-1254 during in vitro maturation induces changes in polyadenylation in a more varied way: as described for gonadotrophins, PCBs induce a more pronounced deadenylation of some of the genes that would deadenylate in control conditions (that is, glucose transporter type 1, connexin-43 and plakoglobin); however, at the same time, a longer poly(A) tail is observed at the 3 '-end of connexin-32, a gene that normally readenylates during maturation. Finally, another pattern has been observed for heat shock protein 70 , which instead of undergoing a deadenylation process as in control conditions, shows an extension of the tail at the end of in vitro maturation (Pocar et al., 2001b).

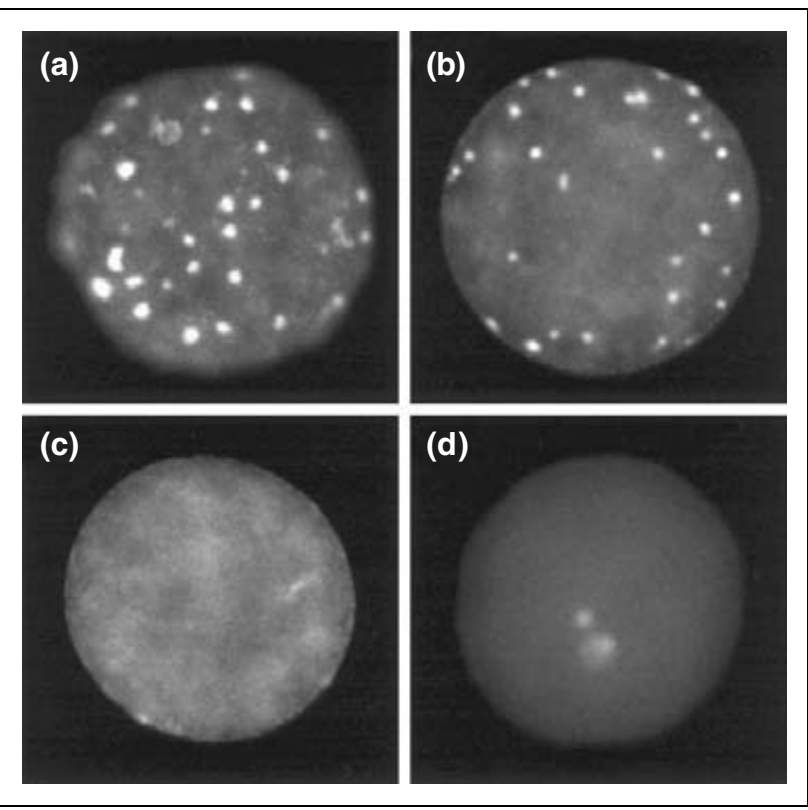

Fig. 5. The cortical granule reaction. Cortical granules are specialized membrane-bound, secretory granules responsible for the slow block of polyspermy in mammalian zygotes. The content of cortical granules makes the zona pellucida 'refractory' to sperm penetration. During oocyte maturation and fertilization, cortical granules follow a characteristic pattern of migration that has been considered as a valuable index of the cytoplasmic maturation and developmental competence. (a) Initially, cortical granules form big clusters distributed throughout the cytoplasm. (b) Upon the resumption of meiosis, the granules become localized in small clusters at the periphery of the ooplasm, until (c) they form a layer of single granules just under the membrane, at the time of ovulation. (d) Finally, the exocytosis of the granules occurs after interaction with the spermatozoa. (Reproduced with permission from Pocar et al., 2001b.)

\section{Disruption of cortical granule redistribution}

A common attribute of cytoplasmic maturation is the migration and redistribution of organelles, including cortical granules, in temporal co-ordination with the nuclear stages (Fig. 5). Most oocytes exposed to A-1254 exhibit delayed migration and dispersal of cortical granules, indicating impaired cytoplasmic maturation. In addition, a significantly higher percentage of fertilized oocytes fail to release cortical granules after sperm penetration and present multiple fertilization after IVF (Pocar et al., 2001b). A similar study conducted on cumulus-free mouse oocytes found that exposure to A-1254 during maturation does not allow spontaneous exocytosis of cortical granules (Greenfeld et al., 1998). It is possible that PCBs block the molecular pathways that trigger exocytosis of cortical granules and consequentially cause polyploidy, as the slow block to polyspermy is not created.

Recent in vitro studies have demonstrated that POPs can affect viability and steroid production of follicular 
cells. As oocyte development and maturation occur within the follicle, endocrine disruptors interfering with steroid production can interfere with ovulation.

TCDD is capable of disrupting human ovarian steroid production by acting directly on the follicular granulosa cells, reducing oestradiol secretion and increasing apoptosis. Furthermore, TCDD may alter cell membrane permeability, disrupting steroid secretion (Heimler et al., 1998). Hirakawa et al. (2000) reported that TCDD, at concentrations considered environmentally relevant $(10 \mathrm{pM})$, significantly downregulates the $\mathrm{FSH}$ receptor in rat granulosa cells, indicating that the effects of TCDD on steroidogenesis may be attributable to downregulation of the gonadotrophin receptor. Recent data on farm animals show that TCDD decreases both progesterone and oestradiol secretion by granulosa cells in pigs, in a dose-dependent manner, by altering the activity of enzymes involved in the steroid biosynthesis cascade (Gregoraszczuk, 2002). The same study indicates the presence of cross-talk between the AhR and the oestrogen receptor pathways in follicular cells in pigs. Two recent studies investigating the effects of PCBs in follicular cells in pigs have revealed that PCBs 126 and 153 have dioxin-like and non-dioxin-like activity, respectively (Wojtowicz et al., 2000, 2001). Both PCBs 153 and 126 alter steroid secretion in follicular cells. PCB 153 decreases oestradiol secretion and increases progesterone secretion, indicating that it causes the disruption of the aromatization process. In contrast, PCB 126 is able to induce only the increase of progesterone with no effect on oestradiol secretion by granulosa cells. This finding differs from that previously observed for TCDD, indicating the presence of a different mechanism of action, at least in part. In agreement with this hypothesis, recent investigations indicate that $A h R$ is not directly involved in the effects exerted by PCB mixtures on bovine cumulus-oocyte complexes (Fischer et al., 2001). Despite cumulus granulosa cells expressing the AhR signalling components, exposure to A-1254 during the maturation period is unable to activate the AhR signal transduction pathway. These findings are consistent with previous observations in mice demonstrating that in vivo exposure to different well-known activators of the AhR (the polycyclic aromatic hydrocarbons, benzo(a)pyrene, 3-methylcholantrene and 7,12dimetylbenz(a)anthracene) induces oocyte destruction in the ovary of both Ah-responsive and Ah-non-responsive strains (Mattison and Nightingale, 1982).

\section{Conclusions and future directions}

The published data clearly indicate that POPs (singly or in combination) disrupt mammalian oocyte maturation and follicle physiology even at very low concentrations. However, most of the data presently available derive from experiments performed on laboratory species or in vitro models; therefore, extrapolations to other species or situations should be done with caution. The lack of information on the metabolism and tissue distribution of these chemicals, which greatly depend on species physiology, concentrations and duration of exposure, as well as interactions between single components of the complex mixtures present in the environment, means care should be taken before final conclusions are drawn. Moreover, the specific cellular pathways activated by these compounds are still unclear. Therefore, the search for the specific mechanisms involved in the ovotoxicity and metabolism of POPs should be the focus of further research in this field. In addition, future studies should systematically identify environmental chemicals that can disrupt normal development and function of the reproductive system. Currently, only about 60 environmental pollutants have been identified as endocrine disruptors (Colborn et al., 1993; Toppari et al., 1996) and most of these have been identified accidentally, rather then as a result of an exhaustive screening process. Such widespread screening of all potentially toxic compounds will require the identification of appropriate biomarkers to be used for risk assessment in mammals, and the development of relevant in vitro markers of reproductive toxicity.

\section{References}

Key references are identified by asterisks.

Abbassy MS, Ibrahim HZ and el-Amayem MM (1999) Occurrence of pesticides and polychlorinated biphenyls in water of the Nile river at the estuaries of Rosetta and Damiatta branches, north of Delta, Egypt Journal of Environmental Science and Health B 34 255-267

Allen JR, Barsotti DA, Van Miller JP, Abrahamson LJ and Lalich JJ (1977) Morphological changes in monkeys consuming a diet containing low levels of 2,3,7,8-tetrachlorodibenzo-p-dioxin Food and Cosmetic Toxicology 15 401-410

Alm H, Torner H, Tiemann U and Kanitz W (1998) Influence of organochlorine pesticides on maturation and postfertilization development of bovine oocytes in vitro. Reproductive Toxicology 12 559-563

Ayotte P, Dewailly E, Ryan JJ, Bruneau S and Lebel G (1997) PCBs and dioxin-like compounds in plasma of adult Inuit living in Nunavik (Arctic Quebec) Chemosphere 34 1459-1468

Bal HS (1984) Effect of methoxychlor on reproductive systems of the rat Proceedings Society Experimental Biology and Medicine 176 187-196

Ballschmiter K, Rappe C and Buser HR (1989) Chemical properties, analytical methods and environmental levels of PCBs, PCTs, PCNs and PBBs. In Halogenated Biphenyls, Terphenyls, Naphtalenes, Dibezodioxins and Related Products pp 47-102 Eds RD Kibrough and AA Jensen. Elsevier Science, New York

Barsotti DA, Marlar RJ and Allen JR (1976) Reproductive dysfunction in rhesus monkeys exposed to low levels of polychlorinated biphenyls (Aoroclor 1248) Food and Cosmetic Toxicology 14 99-103

Barsotti DA, Abrahamson LJ and Allen JR (1979) Hormonal alterations in female rhesus monkeys fed a diet containing 2,3,7,8-tetrachlorodibenzop-dioxin Bulletin Environmental Contamination Toxicology 21463 469

Bhatt RV (2000) Environmental influence on reproductive health International Journal of Gynaecology and Obstetrics 70 69-75

Boyle AW, Silvin CJ, Hassett JP, Nakas JP and Tanenbaum SW (1992) Bacterial PCB biodegradation Biodegradation 3 2-3

Brevini-Gandolfi TAL, Colciago A, Favetta LA, Celotti F and Negri Cesi $P$ (1999a) Possible effects of xenobiotics on aromtase activity and its mRNA stability in developing rat hypothalamus Molecular and Cellular Endocrinology 155193 (Abstract) 
*Brevini-Gandolfi TA, Favetta LA, Mauri L, Luciano AM, Cillo F and Gandolfi F (1999b) Changes in poly(A) tail length of maternal transcripts during in vitro maturation of bovine oocytes and their relation with developmental competence Molecular Reproduction and Development 52 427-433

*Brevini-Gandolfi TAL, Favetta LA, Mauri L, Cillo F, Luciano AM and Gandolfi F (1999C) Characterisation of mRNA polyadenylation changes during bovine oocyte maturation and effect of IVM conditions Biology of Reproduction 60213 (Abstract)

Brevini-Gandolfi TA and Gandolfi F (2001) The maternal legacy to the embryo: cytoplasmic components and their effects on early development Theriogenology 55 1255-1276

Buccione R, Schroeder AC and Eppig JJ (1990) Interactions between somatic cells and germ cells throughout mammalian oogenesis Biology of Reproduction 43 543-547

*Burbach KM, Poland A and Bradfield CA (1992) Cloning of the Ahreceptor CDNA reveals a distinctive ligand-activated transcription factor Proceedings National Academy of Sciences USA 89 8185-8189

Campagna C, Sirard MA, Ayotte P and Bailey JL (2001) Impaired maturation, fertilization, and embryonic development of porcine oocytes following exposure to an environmentally relevant organochlorine mixture Biology of Reproduction 65 554-560

Chaffin CL, Peterson RE and Hutz RJ (1996) In utero and lactational exposure of female Holtzman rats to 2,3,7,8-tetrachlorodibenzo- $p$ dioxin: modulation of the estrogen signal Biology of Reproduction $\mathbf{5 5}$ $62-67$

Chaffin CL, Stouffer RL and Duffy DM (1999) Gonadotropin and steroid regulation of steroid receptor and aryl hydrocarbon receptor messenger ribonucleic acid in macaque granulosa cells during the periovulatory interval Endocrinology 140 4753-4760

Clarkson TW (1995) Environmental contaminants in the food chain American Journal of Clinical Nutrition 61 682S-686S

Colborn T, vom Saal FS and Soto AM (1993) Developmental effects of endocrine-disrupting chemicals in wildlife and humans Environmental Health Perspectives 101 378-384

Coulston F (1985) The dilemma of DDT Regulations in Toxicology and Pharmacology 5 329-331

Crisp TM, Clegg ED, Cooper RL et al. (1998) Environmental endocrine disruption: an effects assessment and analysis Environmental Health Perspectives 106 Supplement 111-56

Cummings AM and Gray LE, Jr (1987) Methoxychlor affects the decidual cell response of the uterus but not other progestational parameters in female rats Toxicology and Applied Pharmacology 90 330-336

Cummings AM, Metcalf JL and Birnbaum L (1996) Promotion of endometriosis by 2,3,7,8-tetrachlorodibenzo- $p$-dioxin in rats and mice: time-dose dependence and species comparison Toxicology and Applied Pharmacology 138 131-139

Damiani P, Fissore RA, Cibelli JB, Long CR, Balise JJ, Robl JM and Duby RT (1996) Evaluation of developmental competence, nuclear and ooplasmic maturation of calf oocytes Molecular Reproduction and Development 45 521-534

d'Argy R, Dencker L, Klasson-Wehler E, Bergman A, Darnerud PO and Brandt I (1987) 3,3'4,4'-Tetrachlorobiphenyl in pregnant mice: embryotoxicity, teratogenicity, and toxic effects on the cultured embryonic thymus Pharmacological Toxicology 61 53-57

Davis BJ, Maronpot RR and Heindel JJ (1994) Di-(2-ethylhexyl) phthalate suppresses estradiol and ovulation in cycling rats Toxicology and Applied Pharmacology 128 216-223

Delescluse C, Lemaire G, de Sousa G and Rahmani R (2000) Is CYP1A1 induction always related to AHR signaling pathway? Toxicology $\mathbf{1 5 3}$ 73-82

Denison MS and Wilkinson CF (1985) Identification of the Ah receptor in selected mammalian species and induction of aryl hydrocarbon hydroxylase European Journal of Biochemistry 147 429-435

DeVito MJ and Birnbaum LS (1995) The importance of pharmacokinetics in determining the relative potency of 2,3,7,8-tetrachlorodibenzo- $p$ dioxin and 2,3,7,8-tetrachlorodibenzofuran Fundamental and Applied Toxicology 24 145-148
Dolwick KM, Schmidt JV, Carver LA, Swanson HI and Bradfield CA (1993) Cloning and expression of a human Ah receptor cDNA Molecular Pharmacology 44 911-917

Fingler S, Drevenkar V, Tkalcevic B and Smit Z (1992) Levels of polychlorinated biphenyls, organochlorine pesticides, and chlorophenols in the Kupa River water and in drinking waters from different areas in Croatia Bulletin of Environmental Contamination and Toxicology 49 805812

Fischer B, Hasan A, Kietz S and Pocar P (2001) Ah receptor expression and signal transduction in bovine and rabbit reproductive tissues and embryos Proceedings British Society of Animal Science (Abstract 64)

Gao X, Son DS, Terranova PF and Rozman KK (1999) Toxic equivalency factors of polychlorinated dibenzo- $p$-dioxins in an ovulation model: validation of the toxic equivalency concept for one aspect of endocrine disruption Toxicology and Applied Pharmacology 157107 116

Generoso WM, Stout SK and Huff SW (1971) Effects of alkylating chemicals on reproductive capacity of adult female mice Mutation Research $\mathbf{1 3}$ 172-184

Giavini E, Prati M and Vismara C (1983) Embryotoxic effects of 2,3,7,8tetrachlorodibenzo- $p$-dioxin administered to female rats before mating Environmental Research 31 105-110

Gray LE, Jr and Kelce WR (1996) Latent effects of pesticides and toxic substances on sexual differentiation of rodents Toxicology in Industrial Health 12 515-531

Gray LE, Wolf C, Mann P and Ostby JS (1997) In utero exposure to low doses of 2,3,7,8-tetrachlorodibenzo-p-dioxin alters reproductive development of female Long Evans hooded rat offspring Toxicology and Applied Pharmacology 146 237-244

Greenfeld CR, Xiongqing W and Dukelow WR (1998) Aroclor 1254 does not affect the IVF of cumulus-free mouse oocytes Bulletin of Environmental Contamination and Toxicology 60 766-772

Gregoraszczuk EL (2002) Dioxin exposure and porcine reproductive hormonal activity Cadaude de Saude Publica 18 453-462

*Hafne A-L, Byskov AG, Ynding-Larsen C and Tcerdal A (2000) Response on spontaneous and induced maturation in vitro from estradiol, diethylstilbestrol and octylphenol in mouse oocytes Theriogenology 53 454 (Abstract)

Hankinson O (1995) The aryl hydrocarbon receptor complex Annual Review of Pharmacology and Toxicology 35 307-340

Heimler I, Rawlins RG, Owen H and Hutz RJ (1998) Dioxin perturbs, in a dose- and time-dependent fashion, steroid secretion, and induces apoptosis of human luteinized granulosa cells Endocrinology 139 43734379

Hirakawa T, Minegishi T, Abe K, Kishi H, Inoue K, Ibuki $\mathrm{Y}$ and Miyamoto $\mathrm{K}$ (2000) Effect of 2,3,7,8-tetrachlorodibenzo-p-dioxin on the expression of follicle-stimulating hormone receptors during cell differentiation in cultured granulosa cells Endocrinology 141 1470-1476

Hirshfield AN (1991) Development of follicles in the mammalian ovary International Review of Cytology 124 43-101

${ }^{*}$ Hoffman EC, Reyes H, Chu FF, Sander F, Conley LH, Brooks BA and Hankinson O (1991) Cloning of a factor required for activity of the Ah (dioxin) receptor Science 252 954-958

Hooser SB, Douds DP, DeMerell DG, Hoyer PB and Sipes IG (1994) Long-term ovarian and gonadotropin changes in mice exposed to 4vinylcyclohexene Reproductive Toxicology 8 315-323

Hoyer PB (1999) Ovotoxic environmental chemicals: indirect endocrine disruptors. In Endocrine disruptors. Effects on Male and Female Reproductive Systems pp 57-124 Ed RK Naz. CRC Press, Boca Raton

Hoyer PB and Sipes IG (1996) Assessment of follicle destruction in chemical-induced ovarian toxicity Annual Review of Pharmacology and Toxicology 36 307-331

Hyttel P, Fair T, Callesen H and Greve T (1997) Oocyte growth, capacitation and final maturation in cattle Theriogenology 47 23-32

Jacobson JL, Fein GG, Jacobson SW, Schwartz PM and Dowler JK (1984) The transfer of polychlorinated biphenyls (PCBs) and polybrominated biphenyls (PBBs) across the human placenta and into maternal milk American Journal of Public Health 74 378-379 
Jarrell JF, Bodo L, YoungLai EV, Barr RD and O'Connell GJ (1991) The short-term reproductive toxicity of cyclophosphamide in the female rat Reproductive Toxicology 5 481-485

Johansen HR, Becher G, Polder A and Skaare JU (1994) Congenerspecific determination of polychlorinated biphenyls and organochlorine pesticides in human milk from Norwegian mothers living in Oslo Journal of Toxicology and Environmental Health 42 157-171

Jones KC (1988) Determination of polychlorinated biphenyls in human foodstuffs and tissues: suggestions for a selective congener analytical approach Science of Total Environment 68 141-159

Jonsson HT, Jr, Keil JE, Gaddy RG, Loadholt CB, Hennigar GR and Walker EM, Jr (1975) Prolonged ingestion of commercial DDT and PCB; effects on progesterone levels and reproduction in the mature female rat Archives of Environmental and Contaminant Toxicology 3 479-490

Kavlock RJ and Ankley GT (1996) A perspective on the risk assessment process for endocrine-disruptive effects on wildlife and human health Risk Analysis 16 731-739

Khera KS, Whalen C and Trivett G (1978) Teratogenicity studies on linuron, malathion, and methoxychlor in rats Toxicology and Applied Pharmacology 45 435-444

Kholkute SD and Dukelow WR (1997) Effects of polychlorinated biphenyl (PCB) mixtures on in vitro fertilization in the mouse Bulletin of Environmental and Contaminant Toxicology 59 531-536

Kholkute SD, Rodriguez J and Dukelow WR (1994) Reproductive toxicity of Aroclor-1254: effects on oocyte, spermatozoa, in vitro fertilization, and embryo development in the mouse Reproductive Toxicology 8 487-493

Kimbrough RD (1995) Polychlorinated biphenyls (PCBs) and human health: an update Critical Reviews of Toxicology 25 133-163

Knobil E and Neill JD (1988) The Physiology of Reproduction Raven Press, New York

Koppe JG, Olie K and van Wijnen J (1992) Placental transport of dioxins from mother to fetus. II. PCBs, dioxins and furans and vitamin K metabolism Developmental Pharmacological Therapy 18 9-13

Krogenaes AK, Nafstad I, Skare JU, Farstad W and Hafne AL (1998) In vitro reproductive toxicity of polychlorinated biphenyl congeners 153 and 126 Reproductive Toxicology 12 575-580

Li X, Johnson DC and Rozman KK (1995) Effects of 2,3,7,8tetrachlorodibenzo- $p$-dioxin (TCDD) on estrous cyclicity and ovulation in female Sprague-Dawley rats Toxicological Letters 78 219-222

Lindenau A, Fischer B, Seiler P and Beier HM (1994) Effects of persistent chlorinated hydrocarbons on reproductive tissues in female rabbits Human Reproduction 9 772-780

Linzey AV (1988) Effects of chronic polychlorinated biphenyls exposure on growth and reproduction of second generation white-footed mice (Peromyscus leucopus). Archives of Environmental Contamination and Toxicology 17 39-45

McFarland VA and Clarke JU (1989) Environmental occurrence, abundance, and potential toxicity of polychlorinated biphenyl congeners: considerations for a congener- specific analysis Environmental Health Perspectives $81225-239$

Martijn A, Bakker H and Schreuder RH (1993) Soil persistence of DDT, dieldrin, and lindane over a long period Bulletin of Environmental Contamination and Toxicology 51 178-184

Masuda $Y$, Kagawa R, Kuroki H, Kuratsune M, Yoshimura T, Taki I, Kusuda M, Yamashita F and Hayashi M (1978) Transfer of polychlorinated biphenyls from mothers to foetuses and infants Food and Cosmetic Toxicology 16 543-546

Matikainen TM, Moriyama T, Morita Y, Perez GI, Korsmeyer SJ, Sherr DH and Tilly JL (2002) Ligand activation of the aromatic hydrocarbon receptor transcription factor drives Bax-dependent apoptosis in developing fetal ovarian germ cells Endocrinology 143 615-620

Mattison DR (1980) Morphology of oocyte and follicle destruction by polycyclic aromatic hydrocarbons in mice Toxicology and Applied Pharmacology 53 249-259

Mattison DR (1985) Clinical manifestation of ovarian toxicity. In Reproductive Toxicology pp 109-130 Ed. R Dixon. Raven Press, New York

Mattison DR and Nightingale MS (1982) Oocyte destruction by polycyclic aromatic hydrocarbons is not linked to the inducibility of ovarian aryl hydrocarbon (benzo(a)pyrene) hydroxylase activity in (DBA/2N $\mathrm{X}$ C57BL/6N) F1 X DBA/2N backcross mice Pediatric Pharmacology 2 $11-21$

Meijer GAL, Wagenaar JA, Bree DJ and Spoelstra SF (1997) Riooloverstorten: risico's voor de gezondheid van melkvee. Report number 97028. ID-Lelystad, The Netherlands

Mes J, Marchand L and Davies DJ (1990) Organochlorine residues in adipose tissue of Canadians Bulletin of Environmental and Contaminant Toxicology 45 681-688

Muller WF, Hobson W, Fuller GB, Knauf W, Coulston F and Korte F (1978) Endocrine effects of chlorinated hydrocarbons in rhesus monkeys Ecotoxicology and Environmental Safety 2 161-172

Nishimura M, Shiota K, Tanimura T, Mizutani T, Matsumoto $M$ and Veda M (1977) Levels of polychlorinated biphenyls and organochlorine insecticides in human embryos and fetuses Paediatrician 6 45-47

Pauwels A, Covaci A, Delbeke L, Punjabi U and Schepens PJ (1999) The relation between levels of selected PCB congeners in human serum and follicular fluid Chemosphere 39 2433-2441

Peterson RE, Theobald HM and Kimmel GL (1993) Developmental and reproductive toxicity of dioxins and related compounds: cross-species comparisons Critical Reviews in Toxicology 23 283-335

Petroff BK, Gao X, Rozman KK and Terranova PF (2000) Interaction of estradiol and 2,3,7,8-tetrachlorodibenzo-p-dioxin (TCDD) in an ovulation model: evidence for systemic potentiation and local ovarian effects Reproductive Toxicology 14 247-255

Pocar P, Perazzoli F, Luciano AM and Gandolfi F (2001a) In vitro reproductive toxicity of polychlorinated biphenyls: effects on oocyte maturation and developmental competence in cattle Molecular Reproduction and Development 58 411-416

* Pocar P, Brevini TAL, Perazzoli F, Cillo F, Modina S and Gandolfi F (2001b) Cellular and molecular mechanisms mediating the effects of polychlorinated biphenyls on oocyte developmental competence in cattle Molecular Reproduction and Development $60535-541$

Poland A and Knutson JC (1982) 2,3,7,8-tetrachlorodibenzo-p-dioxin and related halogenated aromatic hydrocarbons: examination of the mechanism of toxicity Annual Review of Pharmacological Toxicology 22 517-554

${ }^{*}$ Rhind SM, Smith A, Kyle CE, Telfer G, Martin G, Duff E and Mayes RW (2002) Phthalate and alkyl phenol concentrations in soil following applications of inorganic fertiliser or sewage sludge to pasture and potential rates of ingestion by grazing ruminants Journal of Environmental Monitoring 4 142-148

Richards JS (1980) Maturation of ovarian follicles: actions and interactions of pituitary and ovarian hormones on follicular cell differentiation Physiological Reviews 60 51-89

Richter JD (1996) Dynamics of poly(A) addition and removal during develolopment. In Translational Control pp 481-503 Eds J Hershey, M Mathews and N Sonenberg. Cold Spring Harbor Laboratory Press, New York

Rivero-Rodriguez L, Borja-Aburto VH, Santos-Burgoa C, Waliszewskiy S, Rios C and Cruz V (1997) Exposure assessment for workers applying DDT to control malaria in Veracruz, Mexico Environmental Health Perspectives 105 98-101

Robles R, Morita Y, Mann KK, Perez GI, Yang S, Matikainen T, Sherr DH and Tilly JL (2000) The aryl hydrocarbon receptor, a basic helixloop-helix transcription factor of the PAS gene family, is required for normal ovarian germ cell dynamics in the mouse Endocrinology 141 450-453

Ronnback C (1991) Effects of 3,3',4,4'-tetrachlorobiphenyl (TCB) on ovaries of foetal mice Pharmacological Toxicology 68 340-345

Ronnback C and de Rooij DG (1994) Effects of 3,3',4,4'-tetrachlorobiphenyl on foetal germ cells in two mouse strains after repeated treatment of the dams during and after pregnancy Pharmacological Toxicology $\mathbf{7 4}$ 287-293

*Safe SH (1986) Comparative toxicology and mechanism of action of polychlorinated dibenzo- $p$-dioxins and dibenzofurans Annual Review of Pharmacological Toxicology 26 371-399

*Sharara FI, Seifer DB and Flaws JA (1998) Environmental toxicants and female reproduction Fertility and Sterility 70 613-622 
Silbergeld EK and Mattison DR (1987) Experimental and clinical studies on the reproductive toxicology of 2,3,7,8-tetrachlorodibenzo- $p$-dioxin American Journal of Industrial Medicine 11 131-144

Smialowicz RJ, Andrews JE, Riddle MM, Rogers RR, Luebke RW and Copeland CB (1989) Evaluation of the immunotoxicity of low level PCB exposure in the rat Toxicology 56 197-211

Smits-van Prooije AE, Lammers JHCM, Waalkens-Berendsen DH and Kulig BM (1992) Effects of 3,4,5,3', 4', 5'-hexachlorobiphenyl alone and in combination with $3,4,3^{\prime}, 4^{\prime}$-tetrachlorobiphenyl on the reproduction capacity of rats Organohalogen Compounds 10 217-219

Son DS, Ushinohama K, Gao X, Taylor CC, Roby KF, Rozman KK and Terranova PF (1999) 2,3,7,8-tetrachlorodibenzo- $p$-dioxin (TCDD) blocks ovulation by a direct action on the ovary without alteration of ovarian steroidogenesis: lack of a direct effect on ovarian granulosa and thecal-interstitial cell steroidogenesis in vitro. Reproductive Toxicology 13 521-530

Swain WR (1991) Effects of organochlorine chemicals on the reproductive outcome of humans who consumed contaminated Great Lakes fish: an epidemiologic consideration Journal of Toxicology and Environmental Health 33 587-639

Telford NA, Watson AJ and Schultz GA (1990) Transition from maternal to embryonic control in early mammalian development: a comparison of several species Molecular Reproduction and Development 26 90-100

Thomas JA (1993) Toxic responses of the reproductive system. In Toxicology pp 484-520 Eds M Amdur, J Doull and C Klassen. McGraw-Hill, New York

Toppari J, Larsen JC, Christiansen P et al. (1996) Male reproductive health and environmental xenoestrogens Environmental Health Perspectives 104 Supplement 4 741-803

Trapp M, Baukloh V, Bohnet HG and Heeschen W (1984) Pollutants in human follicular fluid Fertility and Sterility 42 146-148

Tsutsumi $O$, Uechi $H$, Sone $H$, Yonemoto J, Takai $Y$, Momoeda $M$, Tohyama C, Hashimoto S, Morita M and Taketani Y (1998) Presence of dioxins in human follicular fluid: their possible stage-specific action on the development of preimplantation mouse embryos Biochemical Biophysical Research Communications 250 498-501

Vassalli JD and Stutz A (1995) Translational control. Awakening dormant mRNAs Current Biology 5 476-479

Vos JG and van Loveren H (1995) Markers for immunotoxic effects in rodents and man Toxicological Letters 82-83 385-394

Wild SR and Jones KC (1992) Organic chemicals entering agricultural soils in sewage sludges: screening for their potential to transfer to crop plants and livestock Science of Total Environment 119 85-119

Wojtowicz AK, Gregoraszczuk EL, Lyche IL and Ropstad E (1999) Effects of in vitro treatment of nondioxin-like (PCB 153) and dioxin-like (PCB 126) polychlorinated biphenyls on follicular cells steroidogenesis Third Conference of the European Society for Domestic Animals Reproduction 95 (Abstract)

Wojtowicz AK, Gregoraszczuk EL, Lyche JL and Ropstad E (2000) Time-dependent and cell-specific action of polychlorinated biphenyls (PCB 153 and PCB 126) on steroid secretion by porcine theca and granulosa cells in mono- and co-culture Journal of Physiological Pharmacology 51 555-568

Wojtowicz A, Ropstad E and Gregoraszczuk E (2001) Estrous cycle dependent changes in steroid secretion by pig ovarian cells in vitro to polychlorinated biphenyl (PCB 153) Endocrinological Regulations 35 223-228

Wolf CJ, Ostby JS and Gray LE, Jr (1999) Gestational exposure to 2,3,7,8-tetrachlorodibenzo-p-dioxin (TCDD) severely alters reproductive function of female hamster offspring Toxicological Science $\mathbf{5 1}$ 259-264

Yang JH, Vogel C and Abel J (1999) A malignant transformation of human cells by 2,3,7,8-tetrachlorodibenzo-p-dioxin exhibits altered expressions of growth regulatory factors Carcinogenesis 20 13-8

Zhu BT and Conney AH (1998) Functional role of estrogen metabolism in target cells: review and perspectives Carcinogenesis 19 1-27 